\title{
Exploring the dimensions of flow and the role of music in professional ballet dancers
}

\author{
Clorinda Panebianco-Warrens ${ }^{\mathrm{a}}$ \\ ${ }^{a}$ University of Pretoria, Clorinda.Panebianco-Warrens@up.ac.za
}

\begin{abstract}
Flow, also known as the 'zone', is a positive enjoyable psychological state often linked to optimal performance. The aim of this study is to explore professional ballet dancers' subjective experiences of flow in a current performance context. Csikszentmihalyi's (1990) model of the flow state is used for its applicability to professional ballet dancers. Furthermore, the study aims to gain an understanding of the role of music in dancers' experience of flow.
\end{abstract}

Seventeen ballet dancers from two South African ballet companies shared their experiences in separate semi-structured interview sessions. The interviews took place during the 2013 productions of Don Quixote in Johannesburg and Camille in Cape Town respectively, so that the dancers could draw on recent performance experience in their recollection of flow. The interviews were transcribed and analysed deductively and inductively using interpretative phenomenological analysis.

The study found resemblances with Csikszentmihalyi (1990) dimensions of flow in professional ballet dancers. The three dimensions that stood out as most predictive of flow in this study were the merging of action and awareness, autotelic experience and loss of selfconsciousness. Music clearly played an important role in dancers' experience of flow. Dancers' varying levels of awareness of and engagement with music during flow could suggest differing intensities in flow among ballet dancers. The study argues that processing music places an extra demand on dancers' concentration, which presents a unique insight into their experience of flow.

\section{Keywords}

Flow, ballet dancers, musicians, optimal experience, dimensions of flow

\section{Introduction and background}

"I feel I'm in a better place when I'm in the zone (flow), I don't have to think, I just start doing what I do, ... then it just happens. You're almost on automatic pilot and you're, ... without thinking you're thinking quicker that you actually think because the back of your mind is on top of everything. It is beautiful." (principle dancer) 
Flow (also known as the 'zone') is a concept developed by Csikszentmihalyi (1990) following a series empirical studies exploring descriptions of positive experiences from doing an activity that results in complete immersion, to the point of losing awareness of time, surrounding, and all other things, except the activity itself. Flow is also experienced when one is deeply involved in a task, performing at the peak of ability under high levels of concentration. In other words, being able to achieve flow in high skill investment activities that typically involve commitment, discipline, sacrifice, and responsibility, such as ballet, sport and music, can elevate an experience to higher levels of enjoyment and achievement. The result of flow is heightened feelings of well-being, improved self-concept and more objective, less critical self-judgment of performance (Swann, Keegan, Piggot and Crust, 2012: 808). Flow implies a change in the state of consciousness, or disengagement from self and time, and involves a temporary "separation or alteration" of what is regarded as everyday mental processes (Butler, 2006:45, Csikszentmihalyi, 1990). The contrast of flow is a typical everyday state of mind which Baumgardner and Crother (2009:53) term normal "8-to-5 mind". In our 8-to-5 minds we often have trouble focusing, we daydream, are worried about our performance and what others think, experience negative emotions and stress accumulates. Csikszentmihalyi (1990) himself acknowledged that flow is a very difficult subjective psychological concept to quantify and that it is important not to reify flow. The concept of flow "describes a complex psychological state that has important consequences for human life. Any measure of flow we create will only be a partial reflection of this reality" (Csikszentmihalyi, 1990:183). 


\section{Theoretical Background}

Based on numerous studies of flow in various contexts, using questionnaires and interviews, similar results were found among a variety of professions and leisure groups. Flow is considered to be universal across cultures (Delle Fave, Massimini and Bassi, 2011). Csikszentmihalyi (1990) and Jackson and Csikszentmihalyi (1999) distributed the characteristics of flow into nine dimensions. These dimensions are: challenge-skill balance (the activity should be challenging yet within the ability of the individual), action-awareness mergence (often linked to an ecstatic state or being completely immersed with the activity), clear goals (clear understanding of what is required for a successful outcome), unambiguous feedback (immediate positive feedback from self and/or other), concentration on the task at hand (total focus on the task with no extraneous thoughts), sense of control (feeling of being incomplete control of self), loss of self-consciousness (free from inner criticism and selfdoubt), transformation of time (time seem to pass either very quickly or very slowly, a distortion of time perception) and autotelic experience (intrinsically rewarding experience achieved from doing an activity for its own sake). (Csikszentmihalyi, 1990; Jackson and Csikszentmihalyi, 1999; Fritz and Avsec, 2007.)

Since approximately 1992, a considerable amount of research has been invested in flow, especially in the domain of sport (Jackson, 1992, 1995, 1996; Jackson, Thomas, Marsh and Smethurst, 2001; Kimiecik and Stein, 1992; Russel, 2001; Swann, Keegan, Piggot, and Crust, 2012; Young and Pain, 1999), yet factors that encourage, maintain, prevent or interrupt flow are still not clearly understood. It is also unclear whether the flow process represents stages along a flow continuum from micro-flow to macro-flow, or whether it represents changing intensities of flow during an activity (Wright, Sadlo and Stew, 2007:141). Csikszentmihalyi suggested that it should be possible to identify stages of flow within a flow continuum, 
although this concept has not yet been clarified. There are individual differences in how prone people are to experience flow. Ullén, De Manzano, Almeida, Magnusson, Pedersen, Nakamura, Csikszentmihalyi, and Madison (2012) found a positive association between those prone to flow and conscientiousness and negative association with neuroticism and trait anxiety.

While the characteristics of flow have been widely studied in sport, it is unclear how activities that induce flow differ from non-flow experiences in sport and other domains (Bakker, 2005; Lamont, 2012: 575; Swann et al., 2012: 808). Three issues have received focus in literature on flow in sport in particular: understanding the experience of flow through the eyes of the athlete; exploring factors that influence flow; and, investigating the potential of controlling and manipulating flow (Swann et al., 2012: 808). It is rather surprising that very few studies have focused on flow in the domain of artistic performance, such as ballet and music (NordinBates, in Murphy, 2012: 89). Sport and performing arts share many similarities, both activities require long hours of practice over many years, occur in front of an audience, require intrinsic motivation, and mental skills like concentration, anxiety management and thought control. The similarities between sport and professional dance is evident in that for both dancers and athletes their bodies are their instruments, both require intense physical training (Klockare, Gustafsson and Nordin-Bates, 2011:277). However, being a professional dancer requires more than being a good technician. The psychological and attentional demands on a professional dancer are many, for example, expression of emotion, presentation, creativity, artistry, communication and rapport with an audience (Sinnamon et al., 2012:9). The subjective differences in the experience of flow may differ between performing arts and sport, (Sinnamon et al., 2012), which warrants qualitative research into the phenomenon. 
Very few studies have examined the qualitative experience and nature of flow among ballet dancers. Hefferon and Ollis (2006) explored characteristics, facilitators and inhibitors of flow by interviewing nine professional male and female dancers specializing in ballet, contemporary, jazz, Irish and Canadian dance. Their study showed that dancers experience three dimensions of flow: autotelic experience, challenge versus skill and absorption in the task. They found that experiences of flow was either facilitated or inhibited by confidence, music and choreography, pre-performance routine, costumes and make-up, stage setting, and relationships with others. However, a limitation of this study is that it does not focus on ballet dancers alone and includes other dance genres. Jeong's (2012) doctoral thesis, a mixed methods study, examines dancers' use of imagery to enhance flow. The correlational study examined the use of flow and imagery by professional ballet dancers during performance and training. An imagery intervention was developed and tested for efficacy in terms of flow, anxiety and performance. Overall, results showed that dancers experienced flow and used different kinds of imagery for a variety of purposes. Jeong and Hefferon and Ollis (2006) were valuable sources, as theirs were the only two sources that qualitatively explored subjective experiences of flow by dancers, however, neither focused exclusively on ballet dancers nor elaborated on the role of music in the experience of flow.

Exploring dancer's experience of flow from an artistic viewpoint is complicated from various perspectives. It is probable that dancers' multi-sensory experience of flow is embedded and intertwined in complex interactions with the physical and auditory environment. Bresler (2006: 400) suggests that moving and experiencing never occurs in a vacuum but as part of a physical context. Bodily dimensions are experienced in the following perceptual modalities: proprioception which is characterized as a sense of the state, posture, movement and orientation of the body in space; exteroception is the body's inner state 'externalised' (the 
inner states are expressed in movement and in reaction to sounds and music); and interoception (the state of the body itself, for example being conscious of the muscular system). Bresler (2006:33) writes that musical performance involves a tri-directional relationship between the music one rehearses and plays, which then draws on ones own inner ideas and emotions, and this is then communicated with the audience in an embodied aesthetic space. The act of communication between a performer, verbal or musical, involves a blurring of the performer's sense of self in a complex state of embodied cognition and affect. Legrand and Ravn (2009) explore subjectivity in bodily movement in dancers and argue that subjectivity is expressed bodily. They contend that dancers experience states of the external world (e.g. sound and music) not only through exteroception (audition) but through their movements. Legrand and Ravn (2009:400) argue for an intertwining of proprioception, interoception and exteroception, especially in ballet dancers who integrate inner and outer sensations. In ballet, music is not only for creating a structure for movements (or steps) or mirroring the music in choreography, but ballet dancers' experience of the music is as "an experience of their hearing and moving body", in other words, ballet dancers hear through their moving bodies more than through their ears (Legrand and Ravn 2009:401). Movement steps and patterns become embodied following many years of engrained practice.

This study intends to extend literature on the subjective experience of flow in ballet dancers within Csikszentimihaly's (1990) framework of the dimensions of flow, and to gain clarity on which dimensions are salient in the experience of flow. Furthermore, it aims to explore the role of music in flow. A qualitative research paradigm will be used for the study. Interpretative Phenomenological Analysis (IPA) explores lived experiences of the participants as experts in their field and aims to capture and explore meanings the participants assign to their experiences (Reid, Flowers and Larkin, 2005). IPA draws strongly on the philosophical 
writing of Edmund Husserl (1859-1938) who recognized phenomenology, or the 'sense' of performance, as the 'essence' of performance because it captures the relationship between the performer, music and audience (Holmes and Holmes, 2012:77). Phenomenology is increasingly used in empirical studies aimed at understanding the experience of a performer, which conceives of bodily processes as cognitive, physical and inherently subjective. Holmes and Holmes (2012) contend that any performance involves characteristics unique to the individual and this idiographic foundation is at the heart of performance.

There are various reasons this investigation is aimed at professional ballet dancers. Firstly, the study aims to understand the flow experience of ballet dancers in the context of a current performance (no study of which I am aware has investigated ballet dancers' subjective experience of flow during a performance season). Secondly, given the multi-level attentional demands placed on the ballet dancer during a performance the research aims to explore the role music processing plays in the experience of flow.

\section{Methodology}

Purposive sampling was used in the selection of participants. The participants were 17 professional ballet dancers, ten from the Mzansi South African Ballet Theatre in Johannesburg and seven members of the Cape Town City Ballet. The sample was fairly homogenous and comprised of seven male and ten female dancers, representing varying professional levels ${ }^{1}$ and ethnic groups within the two companies - artist $(n=3)$, senior artist $(n=2)$, soloist $(n=4)$, senior soloist $(n=5)$, principal $(n=2)$, ballet mistress $(n=1)$ (recently

\footnotetext{
${ }^{1}$ A ballet company contracts dancers at varying levels. Artists belong to the Corps de Ballet, dancers at this level are at the lowest rank. Senior artists are often given solo parts but continue to dance as corps member. Soloists and senior soloists dance solos and often learn principle roles as understudies. Principals are the stars of the ballet company and appear in leading roles. The ballet mistress trains, directs and often choreographs for the company.
} 
retired principal). Their dancing experience ranged from approximately two to 25 years. Sixteen of the dancers were South African and received their formative training in South Africa. One principal dancer is British, currently living in South Africa. The Mzansi production of Don Quixotte was performed with recorded music whereas the Cape City Ballet performed Camille with a live orchestra ${ }^{2}$, the Cape Town Philharmonic.

An interview guide was developed consisting of questions around dancers experience and description of flow, and their level of awareness of music during of flow in performance. Semi-structured, open-ended format interviews were conducted during the ongoing performances of Don Quixote ${ }^{3}$ (Johannesburg) and Camille ${ }^{4}$ (Cape Town), so that the dancers could access and discuss the experiences in the context of a recent live performance. I asked the dancers if they were familiar with the concept flow. Only eight dancers were aware of the concept, however, most preferred to use the phrase 'in the zone' rather than flow because the term flow seemed to suggest a flow of movement and music rather than the flow phenomenon. For those dancers who were unfamiliar with the concept I provided a brief explanation in layman's terms of flow (or the 'zone'), based on Csikszentmihalyi's definition of the construct.

The interviews were transcribed verbatim. Each interview was read several times and salient themes noted on the transcript. Both deductive and inductive content analysis was used to identify inherent themes and patterns in the data and provide open coding throughout the text.

\footnotetext{
${ }^{2}$ Due to a shortage of funding for full orchestra it is not uncommon for ballet performances to be staged with recorded music. Mzansi South African Ballet Theatre performed Don Quixote to recorded music whereas Cape Town City Ballet's Camille was accompanied by the Cape Philharmonic Orchestra.

${ }^{3}$ Don Quixote is based on an episode in Cervantes' novel set in Barcelona. It was originally choreographed by Markus Pepita and music composed by Lidwig Minkus.

${ }^{4}$ This production of the ballet Camille is based on the original story by Alexandre Dumas and music by Giuseppe Verdi's La Traviata.
} 
The data was collated in two phases. Firstly, a deductive analysis involved finding themes matching Csikszentmihaly's (1990) dimensions of flow, in other words, a top-down processing matching already available themes and subthemes. The second part of the analysis involved an inductive analysis, which is a bottom-up approach, used to find themes related to the dancer's experience and awareness of the music. The results of the analysis will be discussed in two parts: Dimensions of flow and Music and flow. The data for the first part of the analysis will be discussed under the terminology 'dimensions' (in accordance with Csikszentmihalyi and Jackson's dimensions of flow) and 'subthemes', whereas the terms 'main theme' and 'subtheme' will be used for the second part of the analysis.

\section{Dimensions of flow}

Raw data themes were identified from the ballet dancers' narrative and deductively analysed to fit into Csikszentmihaly's (1990) dimensions flow. The results revealed that professional ballet dancers in this study experienced all nine of dimensions of flow, listed here in order of number times mentioned: (1) merging of action and awareness; (2) autotelic experience; (3) loss of self-consciousness; (4) sense of control; (5) time transformation; (6) challenge-skill balance; (7) total concentration; (8) unambiguous feedback, and (9) clear goals. The least mentioned dimension in this study is clear goals, although this may not mean that the dancers do not experience a clear sense of goals in their performance. Csikszentmihalyi and Getzels (1979) found the relationship between creativity and goals complex. Unlike sport where goals are quantitative, clear goals in dance require a unique combination physical and artistic attributes which are difficult to measure objectively. The flow experience is subjective and illusive and typically does not occur in a linear manner. Identifying dimensions within participant statements was complicated because a single account could reveal several dimensions simultaneously. Table 1 presents a summary table, identifying each of 
dimensions/main themes, number of dancers citing the theme, and subthemes, listed chronologically according to frequency cited.

Table 1. Dimensions of flow/Main theme, number of dancers citing themes within each dimension, and subthemes

\begin{tabular}{|lll|}
\hline Dimensions of flow/ & $\begin{array}{l}\text { Number } \\
\text { Mited }\end{array}$ & Subtheme \\
\hline Action awareness merging (82\%) & 14 & Totally absorbed \\
Autotelic experience (76\%) & 13 & Love of dance \\
& & Feeling elated \\
Loss of self-consciousness (52\%) & 9 & No pain \\
Sense of control (41\%) & 7 & Feel at one with activity \\
& & Feel in control \\
Unambiguous feedback (41\%) & 7 & Totally confident \\
Time transformation (35\%) & 6 & Everything goes well \\
Challenge-skill balance (29\%) & 5 & Time speeds up \\
Total concentration (29\%) & 5 & Good technique and a challenge \\
Clear goals (24\%) & 4 & Total concentration \\
& & Knowing it will be successful \\
& & \\
\hline
\end{tabular}

\section{Dimension 1: Merging of action and awareness}

This general dimension, characterized by complete absorption in dance, was mentioned by thirteen dancers $(82 \%)$ and is clearly the most defining feature of their flow experience. Dancers felt as though everything 'came together' through the music, character and movement, and that they were connected to everything and everyone, yet there was a feeling 
of conscious-unconscious awareness. The subtheme in this dimension is being totally absorbed.

Totally absorbed

“... an experience that is completely present, that is not in the moment, ... you're not thinking about what happens, or what just happened, ... you're completely present in each millisecond ... it's difficult to explain 'because' it's very internal, you go very much inside yourself, but at the same time it's completely aware of everything around you ... (3)

I wasn't thinking of what I was doing, it was just happening I felt part of ... an organism on stage; I wasn't separate ... (15)

Dancers seem to experience varying degrees of being present in the moment, some being fully aware of their surroundings and others lost in the moment.

\section{Dimension 2: Autotelic experience}

An autotelic experience refers to an experience which is enjoyable and intrinsically rewarding simply for the sake of the activity. Autotelic experiences lift activities to a different level of personal enjoyment (Csikszentmihalyi, 2009). Having an autotelic experience was the second most cited dimension, by $13(76 \%)$ dancers. Dancing and experiencing flow was described as a positive, intrinsically motivating and rewarding experience which induced an elated state of being. There were three subthemes to this dimension: Love of dance, feeling elated, no pain.

\section{Love of dance}

I'm one of those dancers that really enjoy what I do, like with all my heart, I wake up to dance every day. (12) 
Dancing is clearly a very meaningful positive activity for some dancers, who cannot imagine doing anything else. Experiencing flow in dancing magnifies the positive experience, described as resulting of feelings of elation, happiness and gratification.

\section{Feeling elated}

I felt so happy, like this is my dream and I'm actually living my dream. (7)

Lightness, happiness, it feels like everything's good. (8)

\section{No pain}

Many dancers explained that when in flow they do not experience any pain.

... your whole mind is in bliss of some sort, and your body, you don't feel tired, you don't feel sore. (11)

\section{Dimension 3: Loss of self-consciousness}

The loss of self-consciousness means freedom from negative self-doubt or self-concern. There is total focus and absorption to the point when the performer forgets everything, even the self. This does not mean that someone in flow has abandoned control over the self. There is rather the loss of consciousness of the self (Csikszentmihalyi, 1990). Nine dancers (52\%) mentioned the general dimension of loss of self-consciousness and subsequently loss of the 'conscious' self. This sensation was described under the subtheme 'feel at one with activity'.

\section{Feel at one with the activity}

I was just in my own space, I kind of became the character and my dancing was good ... you kind of forget who you are ... nothing matters when I'm on stage. (2)

Nothing else at that point matters. (9)

You don't feel the stress of having to remember the different steps ..., it just happens and it's amazing. (12) 
Loss of the 'conscious' self reflects a very positive result of flow, which is the loss of selfcriticism and consequently being genuinely pleased with the result.

I didn't notice the spotlights or that the music might have been louder the one night. Afterwards you get back into yourself and "Did that really just happen?" (17)

\section{Dimension 4: Sense of control}

The paradox of control is how Csikszentmihalyi (1990) describes this dimension of the sense of control. However, this complex facet of flow could be present or absent. A sense of control was mentioned by seven dancers (41\%), and described as feeling confident and knowing that the performance would be delivered skillfully. The result is a relaxed and calm sense of confidence that things would work out well and all their hard work would pay off. Dancers described a strong sense of knowing that during flow things would work out well and that they would perform better than usual. There were two subthemes to this dimension: Feel in control, and totally confident.

\section{Feel in control}

When you're in the zone it's easier to cope with it 'cause you're almost on automatic pilot and you're actually thinking quicker than you actually think because the back of your mind is on top of everything. (14)

\section{Totally confident}

It's just a feeling 'everything is going to work now' and you know this is going to work, and you kind of feel amazing. The minute you get to your solo ... and you're just doing everything correctly. (4)

\section{Dimension 5: Unambiguous feedback}

Unambiguous feedback is important in determining whether one is on track. Goals are an intrinsic motivational factor, whereas feedback affirms progress and achievement (Jackson et 
al. 1998). Feedback from the audience, their peers and what was going on at that moment were important to seven dancers (41\%). Feedback can also be a kinesthetic awareness, which refers to receiving "sensory information about one's internal physical awareness" (Jeong, 2012: 137). The subtheme in this dimension is 'everything goes well'.

Everything goes well

All your senses are at that very moment engaged in what you are doing ... your body just moves as it's supposed to. (9)

I think the whole ... comes together, you feel it in your body, and it makes you do amazing things, it's almost like an extra energy. (11)

\section{Dimension 6: Transformation of time}

The transformation of time is one of the most common ways of describing optimal experience. During flow experiences, time appears indistinct and seems to pass by either very quickly or very slowly, although the sensation in the moment is of its having passed unnoticed (Jackson, 1992: 77). This general dimension mentioned by six (35\%) dancers refers to an altered sense of time and was experienced and described as time speeds up. The subtheme under this dimension is 'time speeds up'.

Time speeds up

You don't know you're doing it and all of a sudden it's over, you realize you had done it, but ... it's almost like time stood still because you forgot, ... and then all of a sudden three and a half minutes are over. (6)

... then I realized I'm curtsying and it's already over, ... it just went like this [clicks her finger]. (7) 


\section{General dimension 7: Challenge-skill balance}

The challenge-skills balance is essential to the experience of flow, particularly when a high level of challenge and skills is required. Csikszentmihalyi (1990) explains that if a task is too challenging or difficult, one could experience feelings of stress and anxiety. Five dancers (29\%) alluded to the challenge-skill balance, which is essential to a successful performance. Paradoxically, most of the dancers vividly described their first experiences of flow in their teen years that invariably happened during high pressure circumstances such as a competition or a solo. It would seem that challenge skill balance piqued during high pressure performance situations. The subtheme noticeable in this dimension is 'good technique and a challenge'.

\section{Good technique and a challenge}

Technically you have to be really strong not to think about the technique once you're on stage, ... it's not something you have to think about ... it just happens, so you can just do all the other things, ... portray the character or interact with other characters. (9)

\section{Dimension 8: Total concentration}

The dimension total concentration on the task at hand is the ability to channel complete attention and maintain clear focus throughout the performance, forgetting about intrusive thoughts and pressing demands (Csikszentmihalyi, 1990). This dimension was mentioned by five $(29 \%)$ dancers. There was one subtheme: total concentration.

\section{Total concentration}

I just lose myself ... You're so concentrated on what you're doing that nothing else really matters. (2)

I almost forget I'm on stage. It's almost like you're away from everything, people can talk to you and you're not really getting what they're saying because you're so in the zone of your performance ... it's concentration, it's almost like the way you go away 
from what's actually happening there, you're so concentrated on what you're doing that nothing else really matters... (14)

These quotations illustrate the experience of flow according to the dimensions of flow described by Csikszentmihalyi (1990) and provide a further perspective on how ballet dancers the experience and engage with music during flow.

\section{Dimension 9: Clear goals}

The term clear goals refers to knowing what the objectives of the activity are and having an understanding and awareness of the preparation, planning and details required for optimum performance. Clear focus and purpose occur throughout the performance and keep the performer in a state of peak concentration. This dimension included one subtheme: knowing it will be successful.

... in that moment you can trust that the body will do what it needs to do and you're not kind of in that technical place you're just in (1)

you feel like you're on balance, ... and then when you're on stage and you have that step you just know "this is going to work now" .

\section{Music and flow}

The most significant result from inductive data analysis was that music plays an important role in $88 \%$ of dancers' experience of flow. One of the biggest challenges of analyzing the narrative was trying to understanding at which point during the flow process the dancers were aware of the music, particularly since awareness probably fluctuates during performance. Nevertheless, the salient themes that emerged from the inductive data was that some dancers 
are more acutely aware of music during flow than others, and that music is both a facilitating and inhibiting factor. There are three main themes: Awareness of music, music as facilitator and music as inhibitor. Table 2 includes a summary of the theme, subtheme and raw data themes for music and flow.

Table 2: Music and flow: Theme, Subtheme theme and raw data themes

\begin{tabular}{|l|l|l|}
\hline Theme & Subtheme & Raw data themes \\
\hline $\begin{array}{l}\text { Awareness of music } \\
(15)\end{array}$ & Aware of music & $\begin{array}{l}\text { You're aware of the music because music takes the body } \\
\text { where it wants to be ... I let the music take me. } \\
\text { It's not about the music }\end{array}$ \\
\hline Music as facilitator & $\begin{array}{l}\text { Music as facilitator } \\
\text { Genre } \\
\text { Live orchestra }\end{array}$ & $\begin{array}{l}\text { Music is the profound beginning of everything } \\
\text { I like the music of the classics like Romeo and Juliet } \\
\text { I experience flow with live orchestra }\end{array}$ \\
\hline Music has inhibitor & Dislike music & $\begin{array}{l}\text { I don't experience flow with music I don't like } \\
\text { Easier with live music, with recorded everything is the } \\
\text { same }\end{array}$ \\
\hline
\end{tabular}

\section{Main theme 1: Awareness of music}

Only $11(66 \%)$ dancers claimed that they are aware of the music during flow. Four $(23 \%)$ of these dancers said they are very aware of the music. The remaining six dancers were only marginally aware of the music whereas one dancer claimed to be completely unaware of the music. The stark extremes between dancers' level of engagement (very aware, not at all aware) with the music was an unexpected finding. The dancers who are very aware of the music claimed that music is the "profound beginning of everything", because music "makes you a dancer", and dancers who are not aware of the music do not pay particular attention to it during flow. There are two subthemes: aware of music and not aware of the music. 


\section{Aware of the music}

One dancer articulated that flow was a direct result of the music, an embodied experience of music. It appears that for some dancers, music can be the sole condition for flow.

... you are in the music, so I don't know if it's so much an awareness than a state of being.

I think music is an integral part of dance ... I just find that if the music is absolutely stunning and inspiring it can also help me a lot to ... attain flow. (12)

\section{Not aware of the music}

One dancer claimed that music is not necessary for flow because their attention is rather focused on the audience reaction. In other words, the dimension unambiguous feedback is more important for this dancer.

... for me it's not about the music, for me it's about doing the step, and then the audience reaction, ... that's when I kind of hit the 'spot'. (4)

\section{Music as facilitator}

The results of the inductive analysis revealed approximately 12 factors that facilitate or directly influence flow. Dancing solo is the most cited facilitating factors for attaining flow in ballet dancers. Music is the second most mentioned facilitating factor, substantiated by 14 (82\%) dancers. Other facilitating factors include character, technical challenge, motivation, mental preparation, maturity, genre, audience, and emotion, however, these factors will not be discussed in this article. There are three subthemes: music as facilitator, genre and live orchestra. 


\section{Music as facilitator}

Dancers were affected by the music in various ways. Music helped them to access emotion needed to portray a character. In some cases they experienced strong emotions induced by the music.

You get lost for that moment of time, where you become something else, because it's the music. I think music is the biggest thing for getting into flow. (11)

\section{Genre}

Thirteen dancers (76\%) admitted that genre of the music was a strong facilitating factor. It became apparent that for some dancers music that helped convey or portray a character facilitated flow whereas as other felt that abstract music facilitated flow. This factor possibly relates closely with the general dimension loss of self-consciousness.

I feel when we do abstract work, with no story lines, just the movement and the music and dance, you just find that magical moment that happens, you can't say what happened, you just felt it. I let the music take me $[$ sic $], . .$. that's why I love abstract music, there's no storyline and you let the music can take you where you heart needs to be, and it's so beautiful because you see the movement. I feel it when we do abstract work, with no story lines, just the movement and the music and dance. (5)

Many dancers were more prone to flow if the music represented a story or character. Music, it seems, facilitates dancers transition from one reality into another.

Most of my flow experiences are from music and character ... because you're transported into ... somebody else. (1)

Everything comes together, especially if we are doing a story ballet. You feel like that character or you feel what that character would feel. It's easier when it's a character when I have portray someone else, or emotion is involved. Um, well I definitely think 
music plays a part in it, if you feel the music then I think you can portray it better, I don't know, like, you become the music, that type of thing, I think music definitely has a big influence on that. (3)

All three dancers in these excerpts are acutely aware of the music and are emotionally engaged with it, yet the genre of the music (character or abstract) induce a similar facilitating effect.

\section{Live orchestra}

Twelve (70\%) dancers agreed that a live orchestra contributes a particular palpable energy to the atmosphere, which creates a more optimal flow condition, but it also facilitates an optimal arousal level because of the unpredictability of the conductor and tempi.

With an orchestra it can change like [clicks finger] this, so you've got to be very alert and consciously aware of what he's [conductor] doing. ... there isn't anything like it because ... the sound ... is phenomenal, yet you've got to concentrate a lot more that's for sure. (1)

A live orchestra is different every night, so you don't always know what you're going to get. With a recording you always know ... your body tends to end up moving to that music, and sometimes you stop listening to it ... because you know, it's the same every time. With an orchestra, obviously your conductor might be nervous ... and he might be conducting a little bit faster, so you have to listen more intently, and also, there's an energy that just come from the pit, ... that helps, which we lack when have recordings, which is quite sad. (9)

\section{Music as inhibitor}

Music was cited as the foremost inhibiting factor to flow. The two most prominent subthemes were dislike the music and recorded music. Ten dancers acknowledged that music they dislike would prevent them from entering flow. 


\section{Dislike music}

I've never attained flow with music that don't like ... A rubbish piece of music can prevent you from going anywhere. (12)

Music I dislike can stop flow ... because you're just constantly thinking that you hate this thing [piece]. (6)

It's definitely the genre, the music just makes you feel amazing. There are pieces of music I don't like ... I'm trying to think of a ballet of music that I don't like, ... the music and steps are disjointed, I mean there's no way I could get a sense of flow ... (10)

\section{Recorded music}

Live orchestra was unequivocally preferred over recorded music during performances. Dancer 11 states from the outset that she will generally not feel flow unless there is a live orchestra. Furthermore, she states that in her experience as principle dancer, it is hard work to portray story to recorded (canned) music.

As a principle dancer you need to work so much harder to get the story across when you have canned music, when you don't have live music ... somehow the energy from the pit gives you energy. ... I can't say how incredible it is to have a good live orchestra. (11)

Most dancers agree that recorded music is 'safe' to dance because of the predictability of the recording and set tempi, but it does not contribute to heightened awareness needed for an optimal flow state.

\section{DISCUSSION}

The purpose of this study was to explore the flow experience of professional ballet dancers in two South African dance companies. The study also aimed to investigate the extent to which 
music played a role in the flow experience. Through interviews with 17 professional ballet dancers in-depth information about the subject was gathered and it was found that all the dancers experience flow. A deductive and inductive analysis of the transcripts was conducted to ascertain the prevalence of Csikszentmihalyi's (1990) nine dimensions of flow and to understand the role of music in flow. It was anticipated that ballet dancers' experiences of flow would share similarities with experiences with elite athletes and that music would play a role in the facilitation of flow.

\section{Dimensions}

The results of the deductive analysis of ballet dancers' responses about flow revealed a high level of consistency with Csikszentmihalyi's (1990) nine defining characteristics of flow. These findings are consistent with other qualitative research in sport (Csikszentmihalyi, 1990 Jackson, 1999; Jackson et al., 2001), dance (Hefferon \& Ollis, 2006; Jeong, 2012) and music (Sinnamon et al., 2012). The results of this study showed that the dimensions merging of action and awareness, autotelic experience and loss of self-consciousness represented the bulk of the dancers' flow experience, suggesting that these dimensions may be more central to ballet dancers' experiences. Categorized in order of eminence, the data revealed the following dimensions: merging of action and awareness; autotelic experience; loss of selfconsciousness; sense of control; time transformation; challenge-skill balance; total concentration; unambiguous feedback and clear goals. The dimensions merging of action and awareness, autotelic experience and loss of self-consciousness represented the bulk of the dancers' experience, suggesting that these dimensions may be more central to ballet dancers' experiences. The prominence of the dimension merging of action and awareness reflects the degree of total absorption ballet dancers experience when in flow. This is similar to Jackson (1992:83) who found that the dimensions merging action and awareness, total concentration and sense of control central to $80 \%$ of elite athletes' experiences of flow, which suggests 
similarities between elite athletes and ballet dancers. Dancers in this study emphasised that dancing is an intrinsically rewarding and enjoyable experience, which reflects the second most mentioned dimension in this study, autotelic experience. The autotelic experience is a key feature of flow in the optimal performance setting (Jackson, 1992, 1996; Jackson et al, 2001; Young \& Pain, 1999). Furthermore, ballet dancers in this study cited loss of selfconsciousness as an important dimension of flow, which is contrary to Jackson's $(1992,1996)$ studies in that figure skaters and elite athletes least endorsed this dimension. It is probable that ballet dancers experience a loss of 'self' in their artistic expression of various roles in the portrayal of the music and character in ballet. Hefferon and Ollis (2006: 144) write that dance has been described as a mimicry activity, which allows the participants to escape reality and "create alternate worlds for themselves". The results reveal that dancers experience the dimension of control, or the "paradox of control" as described by Csikszentmihalyi. This dimension of flow is not about worrying about not being in control but rather about a sense or perception of being in control (Jackson 1996:84). Dancers stated that they felt that they needed to surrender or lose themselves in the moment. The moment of "surrender" was similarly found by Elkington (2010: 348) who described it as a "shift in awareness" during the pre-flow moment, when the person is prepared to let go without hesitation.

Music

Music is clearly vitally important to the dancer and is strongly linked to flow, verified by $88 \%$ of the responses. This is consistent with research by Hefferon and Ollis (1996) who found that music and choreography were perceived to be vital factors in enhancing the flow experience. The results of the current study revealed that dancers engage with music with varying levels of awareness. This was most apparent in the way in which some dancers spoke about being emotionally and cognitively engaged with the music. The results revealed that music appeared to be most strongly related to three general dimensions: merging of action and awareness, 
concentration and the sense of control. Interpreting and understanding the inductive data about the role of music in relation to the dimensions of flow is complicated and presented a number of issues, such as, at which point in the experience of flow were dancers referring to the music? For most dancers music is a very important preemptive condition for flow, yet the moment when flow begins the music either disappears or else they remain acutely aware of it. For other dancers music is not an important aspect of flow and they are unaware of music during flow. This suggests that the relationship between flow and music is highly individual and not easily generalizable, furthermore, that flow seems to result from either an internal interaction with the music, or music is experienced as an external cue only. However, it is difficult to tell to what degree these conditions occur.

Music was found to be an important mediating factor which enabled access to a character, which in turn, facilitated flow. This finding is consistent with Hefferon and Ollis' (2006) who similarly found that music and choreography enhanced the occurrence of flow. Music was found to be a prominent facilitating and inhibiting factor in this study. Facilitating factors include the genre and live orchestra. The dancers strongly agreed that they would not experience flow to music they dislike particularly 'modern' or dissonant music, or music they felt they did not understand. This result is consistent with findings by Bodner, Gilboa and Amir (2007, 289) who found that dissonant music or music one dislikes creates tension, which in turn creates excessive arousal and results in overconcentration, resulting in poor performance.

An important finding was that an overwhelming number of dancers from both companies mentioned that dancing to live orchestral music facilitates flow. Dancer's agreed that a live orchestra added an important visceral or embodied component to their performance 
experience. This could possibly be explained by an enhanced sensory arousal effect as a result of dancing with a live orchestra, although there is little research supporting the effect of live orchestra versus recorded music on dancers during performance. Lamont (2011) found associations between strong experiences of music in a live music setting among listeners. This phenomenon needs further empirical investigation because it seems that live music has a direct impact on dancers' experience of flow, which in turn, affects their overall sense of well-being.

Interestingly, although most of the dancers agreed a live orchestra is ideal for the occurrence of flow, it could similarly adversely affect flow, for example, an inexperienced ballet conductor could result in unpredictable tempi, which could either prevent flow or 'snap' a dancer out of flow. Recorded music was cited at as an inhibitor of flow by most dancers. It seems therefore that the predictability of recorded music during live performance does not result in an optimal arousal condition, which prevents flow. These findings further support the ideas of Hefferon and Ollis (2006) and Jeong (2012) who state that flow requires a delicate balance between concentration and immersion in the music, which are important issues related to the experience of flow in professional dancers.

Overall, the results of the inductive analysis revealed that music seem to be an important preemptive condition for flow, and, to a lesser extent, the characteristics of dancers' experience of the music during flow. In other words, those dancers who are acutely aware of music during flow are describing characteristic of their experience and those who are not aware of the music during flow are merely iterating music as conditions for flow to emerge. 
Artistic interaction and communication involves a complex state of embodied cognition and affect involving a process of blurring outer and inner states (Bresler, 2006: 34). Another lens through which one can try to make sense of the role of music in ballet dancers' experience of flow is to consider the findings from an embodied perspective, particularly in relation to Legrand and Ravn's (2009) contention that subjective experiences, particularly dancers' experiences, are perceived and expressed bodily. Dancers' experience of music and movement should be approached with a multidimensional embodied perspective, hence their experience of sound and music is therefore not only through exteroception (audition) but through embodied movement, in other words, they hear through their bodies. This embodied perspective is plausible given that the dancers' narrative of music in this study was found to be particularly related to the dimensions of autotelic experience, loss of self-consciousness, action-awareness and to some degree, control. Although highly conjectural, it is possible that dancers' varying levels of engagement with and awareness of the music suggests that dancers experience music and hearing through their bodies in an embodied sense (Legrand and Ravn, 2009). It is also probable that the analysis revealed individual differences in the flow experience as related to accounts of the role of music in flow, which may too allude to variability's in experienced intensities of flow, suggested by Csikszentmihalyi (1990). In this investigation I may not have done justice to the complexity of these issues but argue that there is a need for further investigation into the role of music and flow. The findings of this study however, could support the notion that flow is a highly individualized, complex experience and that there are variances or differences in intensity in the flow state.

\section{CONCLUSIONS}

The present study has contributed to a more specific and detailed level of understanding of flow in professional ballet dancers and the role music in the experience of flow. Through 
analysis of dancers' descriptions and drawing associations between their descriptions, dimensions of flow and current literature, this study has shown that South African professional ballet dancers' experience of flow has characteristics similar to those identified in previous research on flow in sport (Jackson, 1996; Russell, 2001), dance (Hefferon and Ollis, 2006; Jeong, 2012; Young and Paine, 1999), music (Bakker, 2005; Lamont, 2012; Fritz et al., 2007; Sinnamon et al., 2012) and other domains (Boniface, 2000). The following dimensions of flow were found to be most representative of ballet dancers: merging of action and awareness; autotelic experience; loss of self-consciousness; sense of control; time transformation; challenge-skill balance; total concentration; unambiguous feedback and clear goals. Three dimensions of flow stood out in this study as most prominent characteristics of flow: merging of action and awareness, autotelic experience and loss of self-consciousness.

One of the more significant findings to emerge from the study was that music seems to play a more prominent role in the experience of flow by dancers than has been previously reported. Although performance domains such as dance, music and sport share similarities, I think current research does not adequately address the critical attentional processes music demands of the dancer during performance. It is therefore highly probable that dancers' multi-sensory experience of flow is embedded and intertwined in complex interactions with the physical and auditory environment. I agree with Elkington's (2010) conclusion that flow in ballet dancers should be studied with the aim of understanding individual experiences within an embodied process. This includes closer investigation of how music preempts flow and creates the conditions for flow, as well as what the consequences are. The present study nevertheless makes several contributions to our understanding of flow. 
A few limitations of the study need to be mentioned. Due to the fairly small number of participants, the findings of this study might not be generalizable. Although this study included a representative sample of performance experience of between two to 25 years, the research could have focused on the differences between the experiences of the junior and principal members.

The role of music in flow has been found to be significant in this study, particularly in relation to the dimensions loss of self-consciousness, action awareness, and autotelic experience. Future research could include a deeper investigation into understanding how music facilitates or inhibits flow in ballet dancers. The topic of focus and attention, and the role of music in embodied feeling and action deserve closer attention. The flow state is a multi-phase and multi-dimensional experience consisting of three highly distinct personal phases of experience identified as pre-flow, flow in action and post-flow. Further research could focus on these phases in more depth, particularly regarding the role of music in the individual experiences of flow and aim to further investigate the following questions: How do ballet dancers hear and process music? To what extent does a live orchestra facilitate flow in ballet dancers? Would ballet dancers with musical training have a more developed soundaction relationship? What is the role of musical training in ballet dancers' experience of flow? Are there sound-action association and embodied perceptual experiences unique to ballet dancers?

\section{Summary}

The aims of the study were to explore the subjective experiences of flow by professional South African ballet dancers in a performance context, as well as to explore the role of music 
in the experience of flow. By means of interpretive phenomenological analysis, valuable information and insight was gleaned into ballet dancers' flow experiences. The study concluded that ballet dancers' flow experiences are similar to those of performers in other domains, yet they are unique in the sense that music plays a greater role in flow than was previously thought. The impact of a live orchestra as an important facilitator for the flow experience highlights the value of this resource for ballet dancers in the South African context and deserves further investigation. The study raises a few questions regarding exactly how music and musical training affect dancers' experience of flow. Having a multi-dimensional understanding of flow in ballet dancers could take us a step closer to understanding optimal joyful experiences in the performing arts.

\section{References}

Abuhamdeh, S \& Csikszentmihalyi, M (2009). 'Intrinsic and extrinsic motivational orientations in the competitive context: An examination of person-situation interactions.' Journal of Personality, 77(5):16151635.

Abuhamdeh, S \& Csikszentmihalyi, M (2012). 'The importance of challenge for the enjoyment of intrinsically motivated goal-directed activities.' Personality and Social Psychology Bulletin, 38(3):317-330.

Ainly, M Enger, L \& Kennedy, G (2008). 'The elusive experience of 'flow': Qualitative and quantitative indicators.' International Journal of Educational Research, 47(2):109-121.

Bakker, A B (2005). 'Flow among music teachers and their students: The crossover of peak experiences.' Journal of Vocational Behaviour, 66:26-44.

Baumgardner, S R \& Crothers, M K (2009). Positive psychology. Upper Saddle River, New Jersey: Prentice Hall. 
Bodner, E, Gilboa, A \& Amir, D (2007). The unexpected side-effects of dissonance. Psychology of Music, 35(2):286-305.

Boniface, M R (2000). 'Towards an understanding of flow and other positive experience phenomena within outdoor and adventurous activities.' Journal of Adventure Education and Outdoor Learning, 1(1):55-68.

Bresler, L (2006). Embodied narrative inquiry: A methodology of connection. Research Studies in Music Education, 27:21-43.

Butler, L D (2006). 'Normative dissociation.' Psychiatric Clinics of North America, 29:45-62.

Critien, N \& Ollis, S (2006). 'Multiple engagement of self in the development of talent in professional dancers', Research in Dance Education, 7(2):179-200.

Csikszentmihalyi, M (1990). Flow: The psychology of optimal experience. New York: HarperCollins.

Csikszentmihalyi, M (2009). 'The promise of positive psychology.' Psychological Topics, 18(2):203-211.

Csikszentmihalyi, M \& Hunter, J (2003). 'Happiness in everyday life: The uses of experience sampling.' Journal of Happiness Studies, 4:185-199.

Csikszentmihalyi, M \& Getzels, J W (1989). Creativity and problem finding. In F H Farley \& R W Neperud (eds), The foundations of aesthetics, (91-116). New York: Praeger.

Csikszentmihalyi, M \& Schneider, B (2001). 'Conditions for optimal development in adolescence: An experiential approach.' Applied Developmental Science, 5(3):122-134.

Custodero, L A (2007). 'Observable indicators of flow experience: A developmental perspective on musical engagement in young children from infancy to school age.' Music Education Research, 7(2):185-209. 
Delle Fave, A, Massimini, F \& Bassi, M (2011). Education, learning, and cultural tansmission. In A Delle Fave (Ed), Psychological selection and optimal experience across cultures: Cross-cultural advancements in positive psychology (Vol. 2:235-252). New York: Springer.

De Manzano, Ö, Theorell, T, Harmat, L \& Ullén, F (2010). 'The psychophysiology of flow during piano playing.' Emotion, 10(3):301-311.

Elkington, S (2010). 'Articulating a systematic phenomenology of flow: Experience-process perspective.' Leisure, 34(3):327-360.

Elkington, S (2011). 'What it is to take the flow of leisure seriously.' Leisure, 35(3):53-282.

Ericsson, K A (1998). 'The scientific study of expert levels of performance: General implications for optimal learning and creativity.' High Ability Studies, 9(1):75-100.

Frost, N (2011). Qualitative research methods in psychology: Combining core approaches. Berkshire: McGraw Hill.

Fritz, B S \& Avsec, A (2007). 'The experience of flow and subjective well-being of music students.' Horizons of Psychology, 16(2):5-17.

Geeves, A, McIlwain, D J F, Sutton, J \& Christensen, W (2013). 'To think or not to think: Apparent paradox of expert skill in music performance.' Educational Philosophy and Theory, DOI: 10.10180/00131857.2013.779214.

Getzels, J W \& Csikszentmihaly, M (1976). The creative vision: A longitudinal study of problem finding in art. New York: Wiley. 
Hargreaves, D J, Hargreaves J J \& North, A C (2012). Imagination and creativity in music listening. In D Hargreaves, D Miell \& R MacDonald (eds.) Musical Imaginations: Multidisciplinary perspectives on creativity, performance and perception. Oxford: Oxford University Press, 156-172.

Harmison, R J \& Casto, K V (2012). 'Optimal performance: Elite level performance in “The zone”.' In S.M. Murphy (ed.), The Oxford Handbook of Sport and Performance Psychology. New York: Oxford University Press, 707-724

Hefferon, K M \& Ollis, S (2006). “'Just clicks”: An interpretative phenomenological analysis of professional dancers' experience of flow.' Research in Dance Education, 7(2):141-159.

Hernandez, M D (2011). 'A model of flow experience as determinant of positive attitudes toward online advergames.' Journal of Promotion Management, 17(3):315-326.

Holmes, P \& Holmes C (2013). The performer's experience: A case for using qualitative (phenomenological) methodologies in music performance research. Musicae Scientiae, 17(1):72-85.

Hychner, R H (1985). 'Some guidelines for the phenomenological analysis of interview data.' Human Studies, 8:279-303.

Jackson, S A (1992). 'Toward a conceptual understanding of the flow experience in elite athletes.' Research Quarterly for Exercise and Sport, 67(1):76-90.

Jackson, S A (1995). 'Factors influencing the occurrence of flow state in elite athletes.' Research Quarterly for Exercise and Sport, 67(1):76-90.

Jackson, S A \& Csikszentmihalyi, M (1999). Flow in sports: The keys to optimal experiences and performances. Champaign, IL: Human Kinetics. 
Jackson, S A \& Eklund, R C (2002). 'Assessing flow in physical activity: The flow state scale-2 and dispositional flow scale-2.' Journal of Sport and Exercise Psychology, 24:133-150.

Jackson, S A, Kimiecik, J C, Ford, S K \& March, H W (1998). 'Psychological correlates of flow in sport.' Journal of Sport \& Exercise Psychology, 20(4):359-378.

Jackson, S A, Thomas, P R, Marsh, H W \& Smethurst, C J (2001). 'Relationships between flow, self-concept, psychological skills and performance.' Journal of Applied Sort Psychology, 13(2):129-153.

Jeong, E. (2012). 'The application of imagery to enhance “flow" states in dancers.' PhD thesis, Victoria University.

Juslin, P N \& Västfjäll, D (2008). 'Emotional responses to music: The need to consider underlying mechanisms.' Behavioral and Brain Sciences, 31:559-621.

Kahneman, D (2011). Thinking fast and slow. London: Allen Lane.

Keller, J, Bless, H, Blomann, F \& Kleinböhl, D (2011). 'Physiological aspects of flow experiences: Skillsdemand-compatibility effects on heart rate variability and salivary cortisol.' Journal of Experimental Social Psychology, 47:849-852.

Kimiecik, J C, \& Stein, G L (1992). 'Examining flow experiences in sport contexts: Conceptual issues and methodological concerns.' Journal of Applied Sport Psychology, 4:144-160.

Klockare, E, Gustafsson H, \& Nordin-Bates S M (2011). An interpretative phenomenological analysis of how professional dance teachers implement psychological skills training in practice. Research in Dance Education, $12(2): 277-293$.

Lamont, A (2012). 'Emotion, engagement and meaning in strong experiences of music performance.' Psychology of Music, 40(5):574-594. 
Lanier, L S, Privette, G, Vodanovich, S \& Bundrick, C M (1996). 'Peak experiences: Lasting consequences and breadth of occurrence among realtors, artists, and comparison group.' Journal of Social Behaviour and Personality, 11:781-791.

Legrand D, \& Ravn S (2009). Perceiving subjectivity in bodily movement: The case of dancers. Phenomenological Cognitive Science, 8:389-408.

MacDonald, R, Byrne, C \& Carlton, L (2006). 'Creativity and flow in musical composition: An empirical investigation.' Psychology of Music, 34(3):292-306.

Martin, A J (2008). 'Motivation and engagement in music and sport: Testing a multidimensional framework in diverse performance settings.’ Journal of Personality, 76(1):133-170.

Martin, J \& Cutler, K (2002). 'An exploratory study of flow and motivation in theatre actors.' Journal of Applied Sport Psychology, 14(4):344-352.

Moreno, J A, Cervelló, E \& Gonzáles-Cutre, D (2010). 'The achievement goal and self-determination theories as predictors of dispositional flow in young athletes.' Anales de Psicologia, 26(2):390-399.

Murphy, S M (ed.) (2012). 'The Oxford Handbook of Sport and Performance Psychology.' New York: Oxford University Press.

Nieminen, P, Varstala, V \& Manninen, M (2001). 'Goal orientation and perceived purposes of dance among Finnish dance students: A pilot study.' Research in Dance Education, 1(2):175-193.

Noice, H \& Noice, T (2006). 'What studies of actors and acting can tell us about memory and cognitive functioning.' Current Directions in Psychological Science, 15(1):14-18. 
Nordin Bates, S M (2012). 'Performance psychology in the performing arts.' In S.M. Murphy (ed.). The Oxford handbook of sport and performance psychology. New York: Oxford University Press, 81-116.

O'Neill, S (1999). 'Flow theory and the development of musical performance skills.' Bulletin for the Council of Research in Music Education, 141, Summer:129-143.

Pickard, A \& Bailey, R (2009). 'Crystallising experiences among young elite dancers.' Sport Education and Society, 14(2):165-181.

Pickard, A (2012). 'Schooling the dancer: the evolution of an identity as a ballet dancer.' Research in Dance Education, 13(1):25-46.

Privette, G (1983). 'Peak experience, peak performance, and flow: A comparative analysis of costive human experiences.' Journal of Personality and Social Psychology, 45(6):1361-1368.

Procci, K, Singer, A R, Levy, K R \& Bowers, C (2012). 'Measuring flow experience of gamers: An evaluation of the DFS-2.' Computers in Human Behaviour, 28:2306-2312.

Reid, K, Flowers, P, \& Larkin, M (2005). 'Exploring the lived experience.' The Psychologist, 18:20-33.

Risner, D (2000). 'Making dance, making sense: Epistemology and choreography.' Research in Dance Education, 1(2):155-172.

Russell, W D (2001). 'An examination of flow state occurrence in college athletes.' Journal of Sport Behaviour, 24(1):83-107.

Sinnamon, S, Moran, A \& O'Connell, M (2012). 'Flow among musicians: Measuring peak experiences go student performers.' Journal of Research in Music Education, 60(1):6-27. 
Smith, J A, Flowers, P, \& Larkin, M (2012). Interpretative phenomenological analysis: Theory, method and research. London: Sage.

Stinson, S (1997). 'A question of fun: Adolescent engagement in dance education.' Dance Research Journal, 29(2):49-69.

Swann, C, Keegan, R J, Piggot, D \& Crust, L (2012). 'A systematic review of the experience, occurrence, and controllability of flow states in elite sport.' Psychology of Sport and Exercise, 13:807-819.

Teng, C (2011). 'Who are likely to experience flow? Impact of temperament of character on flow.' Personality and Individual Differences, 50:863-868.

Ullén, F, De Manzano, Ö, Almeida, R, Magnusson, P K E, Pedersen, N L, Nakamura, J, Csikszentmihalyi, M \& Madison, G (2012). 'Proneness for psychological flow in everyday life: Association with personality and intelligence.' Personality and Individual Differences, 52(2):167-172.

Vallo, M A (2013). An investigation of professional ballet dancers experiences of flow and motivations perspectives. M.Phil thesis, University of Birmingham.

Vines, B W, Krumhansl, C L, Wanderley, M M, Dalca, I M \& Levitin, D J (2011). 'Music to my eyes: Crossmodal interactions in the perception of emotions in music performance.' Cognition, 118:157-170.

Voelkl J, Ellis G \& Walker J (2003). Go with the flow. Parks \& Recreation, 38(8):20-29.

Warburton, E C (2002). From talent identification to multidimensional assessment: toward new models of evaluation in dance education, Research in Dance Education, 3(2):103-121.

Walker, C J (2010). 'Experiencing flow: Is doing it together better than doing it alone?' The Journal of Positive Psychology, 5(1):3-11. 
Walker, I J, Nordin-Bates, S M \& Redding, E (2010). 'Talent identification and development in dance: A review of the literature.' Research in Dance Education, 11(3):167-191.

Wong, M M \& Csikszentmihalyi, M (1991). 'Affiliation motivation and daily experience: Some issues on gender differences.' Journal of Personality and Social Psychology, 60(1):154-164.

Wright, J J, Sadlo, G \& Stew, G (2007). 'Further explorations into the conundrum of flow process.' Journal of Occupational Science, 14(3):136-144.

Wrigley, W J \& Emmerson, S B (2013). 'The experience of the flow state in live music performance.' Psychology of Music, 41(3):292-305.

Wulff, H (2008). 'Ethereal expression: Paradoxes of ballet as a global physical culture.' Ethnography, 9:518535.

Young, J A \& Pain, M D (1999). 'The zone: Evidence of a universal phenomenon for athletes across sports.' Online Journal of Sport Psychology, 1(3):21-30. 